\title{
Causation and Observation
}

\section{Document Version}

Accepted author manuscript

Link to publication record in Manchester Research Explorer

\section{Citation for published version (APA):}

Beebee, H. (2009). Causation and Observation. In C. Hitchcock, \& P. Menzies (Eds.), The Oxford Handbook of Causation Oxford University Press.

\section{Published in:}

The Oxford Handbook of Causation

\section{Citing this paper}

Please note that where the full-text provided on Manchester Research Explorer is the Author Accepted Manuscript or Proof version this may differ from the final Published version. If citing, it is advised that you check and use the publisher's definitive version.

\section{General rights}

Copyright and moral rights for the publications made accessible in the Research Explorer are retained by the authors and/or other copyright owners and it is a condition of accessing publications that users recognise and abide by the legal requirements associated with these rights.

\section{Takedown policy}

If you believe that this document breaches copyright please refer to the University of Manchester's Takedown Procedures [http://man.ac.uk/04Y6Bo] or contact uml.scholarlycommunications@manchester.ac.uk providing relevant details, so we can investigate your claim.

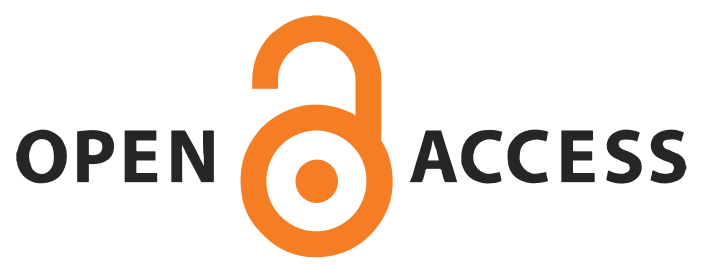




\section{Causation and observation}

Helen Beebee

Please do not cite this version. The published version is:

'Causation and Observation' in H. Beebee, C. Hitchcock and P. Menzies, eds., The Oxford Handbook of Causation (Oxford: OUP, 2009)

\section{Introduction}

Hume argued (or so we are typically taught as undergraduates) that since no intrinsic causal relation can be observed, no idea of causation can be derived from experience, and so causation, conceived as an intrinsic relation between causes and effects, cannot exist - or, at the very least, we have no grounds for believing in its existence. Hence we must either do without the concept all together, or else attempt to analyse causation in such a way that the concept reduces to notions that are empirically respectable. And, given that the only intrinsic relations that count as empirically respectable are spatio-temporal contiguity and temporal priority, our analysis of causation is going to have to appeal to an extrinsic relation, namely, the instantiation by the cause-and-effect pair of a regularity. (For discussion of the intrinsic/extrinsic distinction, see for example Langton and Lewis 1998 and Menzies 1999.)

Hume's (alleged) argument has had a central place in the history of the development of 'Humean' analyses of causation - analyses that construe causation as an extrinsic relation whose obtaining depends on patterns of regularity (see this volume, Chapter 7). It is therefore surprising that its central premise - the claim that causation cannot be observed - has, until relatively recently, been the focus of very little philosophical attention. Instead, the claim was mostly simply accepted as obvious: 'As we have known from Hume', Alvin Goldman says, 'causal connections between events cannot be directly observed' (Goldman 1993, 373) David Armstrong, quoting the same passage, notes that Goldman 'had the bad luck here to stand for whole generations of analytical philosophers' (Armstrong 1997, 211).

There were, of course, some philosophers who denied that causal relations are unobservable. C. J. Ducasse (1965) says, '[t]he plain fact ... is that everyone has perceivedand I say perceived, not inferred - that, for example, a particular tree branch was being caused to bend by a particular bird alighting on it' $(1965,177)$. Elizabeth Anscombe (1971) is rather more well-known for making the same point. Hume 'confidently challenges us', 
Anscombe says, 'to "produce some instance, wherein the efficacy is plainly discoverable to the mind, and its operations obvious to our consciousness or sensation" [Hume [1739-40] 1978, 157-8]. Nothing is easier: is cutting, is drinking, is purring not “efficacy”?' ([1971] 1993, 93). Before both Ducasse and Anscombe, David Armstrong had claimed that 'tactual perception ... gives us immediate awareness of objects making things happen to our body' $(1962,23)$. But he was not trying to make trouble for the Humean, explicitly saying 'I do not think that this necessarily contradicts a Humean or semi-Humean analysis of the nature of causation'(ibid.).

Ducasse and Anscombe were trying to make trouble for the Humean, however. Anscombe rightly identified the claim that causal relations cannot be observed as a central plank in the standard argument for the regularity theory of causation, and in challenging that claim she challenged the standard objection to the kind of 'singularist' view that both she and Ducasse endorsed. (For the purposes of this chapter, 'singularism' is the view that causal relations are intrinsic relations, and so their obtaining does not depend on the relevant events instantiating a regularity.) Ducasse went even further: he explicitly used the allegedly obvious fact that we can observe causation to argue that the Humean view that there is no intrinsic causal relation between causes and effects is false, and singularism is true. 'Causation is therefore not to be confused with causal law, as too often is done', he says. 'An empirically discovered causal law is causal not because it asserts a uniformity of sequence ..., but because it is an induction from perceived occurrences each of which, in its own individual right, was a case of causation and was perceived to be so' (Ducasse 1965, 178). Armstrong later followed Ducasse's lead, writing that the regularity theory of causation 'runs counter to what seem to be the plain facts of experience. Just as we are directly aware of our own mental states, so, it seems to me, we are directly aware of certain cases of token causality. (We could not be directly aware of a cosmic regularity)' (Armstrong 1993, 170).

I shall argue in the course of this chapter that Anscombe and Ducasse may well be right, since the evidence from psychology suggests that we can indeed have experiences that represent the scene before our eyes as causal; and Anscombe was right to claim that this undercuts one traditional way of arguing for a Humean view. On the other hand I shall argue, pace Ducasse and Armstrong, that there is also no good argument from the observability of causal relations to their being intrinsic. In other words, the question of whether or not causation is observable turns out to be largely irrelevant to metaphysical issues concerning the nature and existence of causation. 
I shall proceed as follows. In $§ 2$, I briefly discuss Hume's original argument concerning the absence of a sensory impression of causation. Hume's argument is important not just because of its historical significance in the debate about the observability of causation, but because it raises issues that arise within that debate in a particularly pure form. In $\S 3$, I consider several ways in which psychologists and philosophers have attempted to characterise the sense in which causation might be 'observable', and the implications for the viability of a regularity account of causation. In $\S 4$, I consider whether causation can be experienced in non-visual cases, specifically the experience of touch and the experience of agency. In $\S 5$, I consider briefly whether the observability of causation makes trouble for broadly Humean, non-regularity accounts of causation, namely counterfactual, projectivist and agency theories of causation.

\section{Hume's argument}

Hume's famous discussion of the origin of the idea of necessary connection ([1739-40] 1978, Bk I, Part III, $\S 14$ and [1748/51] 1975, §7) is often cited in discussions of the observation of causation, and it is undeniable that belief in his claim that 'all events seem entirely loose and separate' ([1748/51] 1975, 74) has acted as a strong motivational force for many Humeans. In this section I analyse Hume's argument and argue that, from a contemporary perspective, it is not at all persuasive.

Hume's stated aim, in the sections 'Of the idea of necessary connexion' in the Treatise and first Enquiry, is to find the impression-source of our idea of necessary connection - the thought being that any bona fide idea must have its source in an impression, and so if we are legitimately to deploy the idea of necessary connection in our talk and thought, we must trace it back to its source. At the point where he undertakes this task in the Treatise, he takes himself already to have established that causes must be spatio-temporally contiguous with, temporally prior to and constantly conjoined with their effects ([1739-40] 1978, 74-7). But clearly the idea of causation also includes the idea of necessary connection, and so the source of that idea must be traced to an impression of some kind.

Hume's argument runs roughly as follows.

1. On first observing an event of a given kind, we cannot predict with certainty what effect will follow. 
2. If we could perceive a necessary connection between causally related events, then we would, on first observing the cause, be able to predict with certainty what effect would follow.

Therefore

3. We cannot perceive a necessary connection between causally related events.

Therefore

4. The impression-source of the idea of necessary connection (if there is such a source) cannot be some property or relation available to the senses.

Therefore

5. Meaningful deployment of the idea of necessary connection - if it is possible at all requires that we do not attempt to refer to any necessary connection, or power or force or efficacy, residing 'in the objects', since such usage could only be legitimate if the idea of necessary connection had as its source an impression of sensation (that is, an impression that genuinely detected necessary connections 'in the objects'). The only mindindependent features of the world that the concept of causation can successfully refer to are thus contiguity, temporal priority, and constant conjunction.

Hume's argument has thus been taken to be an argument against singularism: causation, if it exists at all, cannot be conceived as an intrinsic relation between causes and effects.

Three preliminary comments are in order. First, I have ignored some crucial elements in Hume's overall argument. In particular, I have ignored his arguments that neither our control over our thoughts nor our control over our actions can provide the impression-source for the idea of necessary connection. (Hume's grounds here are analogous to those adduced for (3) above: if, for example, I could detect a genuine necessary connection between my wanting or deciding to raise my arm and my actually raising it, I would be able to tell just by experiencing my own act of will that my arm is in fact going to rise up. But I cannot do this; I might discover, for example, that my arm is paralysed and I am unable to raise it.) 
Second, whether Hume really makes the final step in the argument is a controversial question. Galen Strawson and John Wright, for example, both argue that Hume holds that we do refer in our causal talk and thought to genuine, mind-independent, intrinsic causal relations, even though our idea of necessary connection is not derived from an impression of sensation (see Strawson 1989 and Wright 2000; see also my 2006, Chapter 7 for discussion).

Finally, Hume himself does not simply stop at (5). He goes on to claim that the idea of necessary connection does have an impression-source; it's just that the impression is an impression of 'reflection' rather than sensation. Roughly, the idea is that after we have observed cause-and-effect pairs of the same kind several times, we acquire the habit of inferring the effect from the cause. At the very same time, the impression of necessary connection appears: 'when one particular species of event has always, in all instances, been conjoined with another, we make no longer any scruple of foretelling one upon the appearance of the other, and of employing that reasoning, which can alone assure us of any matter of fact or existence. We then call the one object, Cause, the other, Effect' ([1748/51] 1975, 75). Thus, Hume claims, the impression of necessary connection just is the impression that arises when, on observing an event of kind $A$ that we have previously seen to be immediately followed by an event of kind $B$, we infer or come to expect that an event of kind $B$ will occur.

It is controversial whether Hume thinks that, having uncovered the internal impression-source for the idea of necessary connection, meaningful deployment of that idea is possible. On the one hand, he clearly does not have a subjectivist view of causation, which is what would seem to be required if the idea of necessary connection is an essential part of the idea of causation and the former idea refers to an inner mental state. This consideration (amongst others) might lead one to a regularity-theory interpretation of Hume, according to which causation really is just a matter of contiguity, temporal priority and constant conjunction, and not, additionally, a matter of necessary connection. On the other hand, he does not appear to advocate revising the concept of causation in a way that excises the troublesome idea of necessary connection. These considerations might lead one in the direction of a sort of dispositionalist or secondary-quality interpretation, so that causation is defined as that feature of the world that generates the impression of necessary connection; or, alternatively, a projectivist interpretation, according to which causation is a projection of the idea of necessary connection onto a world of brute regularities (see Coventry 2006). (For discussion of these interpretative options, see Beebee 2006, Chapters 5 and 6.) 
Setting these issues aside, how does Hume's argument - as described above - fare from a contemporary perspective? Badly, it turns out, and for a number of reasons. Let's take the steps in the argument one at a time.

The first premise is hard to deny, and not merely because it is hard to see how a decisive counter-example might be found, given that we are exposed to so many regularities from the moment we are born (see $\$ 3.4$ below). Hume's positive argument for (1) is that the existence of a cause and the absence of its effect is always conceivable. This shows that the former does not entail the latter, and so the effect cannot be inferred a priori from the cause.

Several authors have pointed out that (2) is unwarranted, however. J. L. Mackie, for example, calls the kind of necessity that would ground a priori inference from causes to effects (that is, inference from cause to effect just on the basis of one-off observation of the cause) 'necessity,'. (Necessity 2 would have to be some feature of the cause - a 'power of production', as Hume sometimes calls it - such that discerning that feature would enable us to figure out a priori what the cause would bring about.) But he points out that an intrinsic causal connection between causes and effects need not be of the kind that would license $a$ priori inference; he calls a causal connection of this weaker kind 'necessity,'. (Necessity would be a genuine relation between cause and effect, rather than a power residing in the cause.) Mackie argues that (2) only holds for necessity 2 : if we do not presuppose that causal necessity must license a priori inference, but accept instead that it could be a relation such as power or force or efficacy (all of which Hume himself takes to be synonymous with 'necessary connection'), then (2) is false (Mackie 1974, Chapter 1; see also Menzies 1998, 344-5).

As an objection to Hume himself, Mackie's objection arguably fails. Hume takes it for granted that causation is what grounds all of our empirical reasoning: when we draw conclusions about what will happen next, or what is going on in the next room, or what happened in 1066, we are reasoning from causes to effects, or vice versa. For Hume, no relation that failed to be essentially tied to inference could fill that role. To put it another way, Mackie is surely right that, granting (1), we might nonetheless be able to detect a relation between causes and effects, even if we cannot detect anything in the cause itself that licenses inference to the effect. But no such relation could provide the foundation Hume is looking for. A relation that we can only observe to obtain when we see both the cause, $a$, and the effect, $b$, cannot, just by itself, generate any inferences at all, since the next time we come across an $A$, we will have no grounds for supposing that it will similarly cause a $B$. In effect, the problem is that, while we might in principle be able to infer that event $a$ instantiated some 
kind that is (observably) necessarily connected to events of some kind that $b$ instantiated, we will not have any idea what the relevant kinds are; so the next time we come across an event similar in all or some observable respects to $a$, we will not have any idea whether the new event is of the kind that is necessarily connected to $B \mathrm{~s}$. Only sufficient experience of constant conjunction could inform us of what the relevant kinds are. But in that case, the inference from cause to effect would have to rely on 'habit' or 'custom' - that is, inference on the basis of observed regularity. So the detection of necessity ${ }_{1}$ would play no essential role in inference from causes to effects, since habit or custom is perfectly capable of generating the required inference without the aid of such detection.

Mackie's objection is perfectly legitimate, however, when aimed at someone who thinks that Hume's argument establishes the falsity of singularism, which merely requires the existence of an intrinsic causal relation, and not the existence of something essentially tied to inference. If one wants to claim that a causal relation of this kind cannot be observed, then one cannot appeal to (2) in order to establish (3). In fact, many Humeans have taken it to be just obvious, presumably on independent, phenomenological grounds, that (3) is true.

Whether there really are such phenomenological grounds remains to be seen, of course, and I shall return to this question later; but it is worth pointing out that Hume himself does not have anything terribly convincing to say on the matter. He does say, earlier in the Treatise:

'Motion in one body is regarded upon impulse as the cause of motion in another. When we consider these objects with the utmost attention, we find only that one body approaches the other; and that the motion of it precedes that of the other, but without any sensible interval' ([1739-40] 1978, 76-7; my italics). But this is a phenomenological claim that the singularist can simply deny; and as we have seen, Ducasse and Anscombe do deny it. Indeed, one might speculate that Hume is sufficiently wedded to the claim about the foundational status of causation in empirical reasoning that it does not even occur to him to seriously consider, from a purely phenomenological point of view, whether the observable relations between causes and effects might not be restricted to temporal priority and contiguity.

The move from (3) to (4) is perhaps uncontroversial; unfortunately, however, the move from (4) to (5) is highly implausible by contemporary lights. For suppose we grant that there is no sensory impression of necessary connection (whether we read 'necessary connection' as the kind of feature that could in principle generate a priori inference (necessity ${ }_{2}$ ) or simply as an intrinsic causal relation between causes and effects (necessity 1 )). This claim only entails that we cannot meaningfully refer to necessary connections (in either sense) if we adopt a very strict meaning-empiricism, according to which an idea or concept 
simply lacks meaning if it is not grounded in a sensory impression. The view that the meaning of a term must be grounded in direct observational contact with the entity or relation referred to has long been out of favour, for very sensible reasons. (For discussion of this in relation to Hume's argument, see Menzies 1998, 356-9.) So even if Hume were right about (4), there would still be no grounds for believing (5).

All things considered, then, Hume's argument for the claim that we cannot meaningfully refer to necessary connections in nature is utterly unpersuasive from a contemporary perspective; and taken as an argument that we cannot even refer to some intrinsic causal relation between events that is weaker than necessity (such as production or bringing-about) - that is, as an argument against singularism - it is even worse.

Where does this leave the prospects for a Humean who claims support for her view from the unobservability of causation? The best that can be done, I think, would be to argue that there are independent phenomenological grounds for holding that causal relations cannot be observed, and then to attempt to argue that, while this does not provide any justification for the claim that the claim that intrinsic causal relations exist is meaningless, it nonetheless justifies the claim that we have no good grounds for believing in them. Unfortunately, however, whatever the prospects for the second stage of the argument, the prospects for the first stage - for arguing that causation cannot be observed - are not good. I examine the evidence for this in $\S 3$ below.

It is worth noting, however, that there is some evidence that even Hume thought that we can have visual experiences as of one thing causing another. Most of us know that Hume said, 'all events seem entirely loose and separate' ([1748/51] 1975, 74). What is generally forgotten that Hume says this (and similar things) in the context of talking about 'single instances of the operation of bodies' ([1748/51] 1975, 73). In other words, he says that this is how things appear to us in situations where the impression of necessary connection is not present because the habit of inferring the effect from the cause has not yet been established. This leaves open the possibility that, for Hume, once the habit has arisen, and the corresponding impression of necessary connection is present, the phenomenology changes: events which previously seemed loose and separate no longer seem so. In other words, it is entirely possible to attribute to Hume the view that (once the inferential habit has been established) we do, in fact, have experiences as of one event causing another. As Blackburn puts it, we fail to engage with Hume 'if we merely insist, as many thinkers do, that we properly describe the perceived states of affairs in causal terms - see bricks splashing in 
water, balls breaking windows, things pushing and pulling' (Blackburn 1984, 211-2; see also Wright 2000, Kail 2001, and Beebee 2006, Chapter 4).

Of course, for Hume the impression does not detect genuine necessary connections: it is an impression of reflection, arising thanks to the inference we draw from cause to effect, and not an impression of any intrinsic feature of the scene before our eyes. But, once we abandon the claim that an impression that genuinely detected causation would have to license a priori inference from cause to effect, the only justification we can take from Hume for holding that there is no sensory impression of causation is the brute claim that, on first observing them, 'all events seem entirely loose and separate' (the thought being that since exactly the same outward features are present each time, a sensory impression of causation ought to be present on first observing a pair of events of a certain kind, rather than arising only once several instances have been observed). I return briefly to the question whether there is any evidence for the truth of this claim in $\S 3.4$ below.

\section{Experience of causation}

It's a good idea to get a handle on the experience of causation that is independent of our metaphysical views about causation. Indeed, this is mandatory if we are to stand any chance at all of coming to any metaphysical conclusions based on claims about what we 'see' when we look at scenes that are, in fact, causal. For example, it is no good trying to argue that, since there is overwhelming psychological evidence that we perceive causation, and since one cannot perceive that $p$ unless it is true that $p$, eliminativism about causation must be false. The eliminativist will legitimately respond that, whatever the psychological evidence may be, it cannot, just by itself, constitute evidence that there really is any causation. When psychologists talk about the perception of causation, they are not using 'perception' as a success term. (This is obvious from the fact that psychologists happily talk about perception even in cases of illusion.) I shall use 'perception' in this sense throughout, and take it to be synonymous with the notion of causal experience.

Imagine watching a game of snooker. A player lines up her shot, hits the white ball with the cue stick, the white ball moves towards the black ball, and makes contact with it; whereupon the black ball moves towards, and then into, the pocket. Call an experience that just represents the kinematic features of this scene - the positions and movements of the cue stick and the balls - a thin experience. Call an experience, or a belief, that additionally represents the scene as having causal elements - for example, that the impact of the cue stick makes the white ball move or causes it to move - a causal experience or belief. A standard 
(though, as we shall see, mistaken) view amongst philosophers is that Humeans are required to deny that causal experience is possible: we have causal beliefs, but these beliefs must be inferred from thin experiences together with background beliefs - beliefs about regularities, for example.

The argument for this claim goes something like this. For a Humean - or at least for a regularity theorist (see Chapter 7), the causal relation is extrinsic: its obtaining between two particular events $a$ and $b$ depends upon systematic patterns of regularity. But since the regularity itself is manifestly not present in the scene before one's eyes, the causal relation is no part of the visual stimulus on the basis of which one comes to say things like 'I saw the white ball propel the black ball into the pocket' (as opposed to 'I saw the white ball touch the black ball, and then the black ball moved into the pocket'). Hence such a report must be inferred on the basis of the thin, kinematic experience together with antecedently-held beliefs about regularities: it cannot itself be a report of a causal experience. Thus Armstrong writes:

Suppose ... that one starts ... from the premiss that singular causes are no more than instantiations of cosmic, or at least very widespread, uniformities. Then of course it must be the case that recognition of singular causation is a more or less sophisticated inference triggered off in us by the perception of the current sequence plus memory of the outcome of other such sequences. (1997, 213-4; see also Sosa and Tooley 1993, 13 and Cartwright 2000)

The problem with this argument is that it trades on an undefined notion of 'perception'. Suppose that by 'perception of the current sequence' we take Armstrong to be referring to the visual stimulus that elicits causal judgements. Well, visual stimuli quite generally massively underdetermine the representational content of one's experiences (see Fodor 1984). If we define 'perception' in such a way that only the visual stimuli that we respond to count as candidates for being experienced, virtually everything we ordinarily take ourselves to experience would turn out to be inferred rather than experienced. The claim that there are balls on the table, for example, would turn out to be inferred, since the visual stimulus at any given moment only includes whichever faces of the balls happen to be pointing in my direction. So, according to this conception of experience, I experience the facing surfaces of the balls, and infer from that, together with background beliefs, that there really are balls there. 
Of course, the underdetermination of experience by visual stimuli might be taken to show that in a sufficiently broad sense of 'inferred', all causal content is inferred, in the sense that a good deal of cognitive processing is needed for us to get from the visual stimuli to the experience. But this is an unhelpful sense of 'inferred' to use in the debate between those who think that causation is perceived (in the pyschologists' sense) and those who think it is not. Philosophers sometimes talk about whether causation can be the object of 'direct awareness' or whether it can be 'perceived directly' - by which they presumably mean whether the causal relation, like the surface of a snooker ball, can be a visual (or tactile) stimulus (see for example Menzies 1993, 202-3 and Armstrong 1997, 214-5). This may be a legitimate question, but it is a question that cannot plausibly be answered in the absence of an agreed metaphysical story about the nature of causation. It is uncontroversial that, say, the facing surface of a snooker ball is a part of the visual stimulus that results in us seeing the ball while the back is not; but there is no way, independent of an account of the metaphysics of causation, to establish whether the causal relation can be a part of the visual stimulus that results in us seeing a sequence as causal. The singularist may say that it is, while the Humean will disagree; but it is clear that appeals to phenomenology or psychology will not resolve the issue.

We might instead interpret Armstrong as holding that only local features of the sequence can be perceived or experienced; this is a broader notion of perception than the one just discussed, since a local feature (for example the back of a snooker ball) need not be part of the visual stimulus. If locality of a feature is a necessary condition for experience or perception, then Armstrong will of course be right that a regularity view of causation entails that causation cannot be perceived. But, thus interpreted, Armstrong's argument still cannot be deployed as an objection to a regularity view, and for a familiar reason: on this conception of 'perception', we cannot establish whether causation can be perceived without first establishing whether or not the conditions required for causation to obtain are local conditions. So there is no prospect of arguing from the claim that causation can be perceived to the conclusion that the conditions required for causation are all local, since the latter claim is presupposed by the former.

What is needed, then, is a criterion for 'observability' or 'perceivability' or 'causal experience' that will allow us to establish, independently of any prior metaphysical commitments, whether causation can be observed or perceived, or, in other words, whether causal experience is possible. In the next three sub-sections, I discuss three such criteria. 


\subsection{Causal perception and 'encapsulation'}

Imagine watching an image on a screen of two coloured squares: a green one on the left, and a red one in the centre. The green square moves to across the screen towards the red one and stops when they touch, whereupon the red square moves off in the same direction - to the right. (This is known by psychologists as a 'launching event'.)

How would you describe your experience? Albert Michotte, in his The Perception of Causality ([1946] 1963), ran the experiment, and elicited people's responses. Michotte reported that 'the observers see object $A$ bump into object $B$, and send it off (or 'launch' it), shove it forward, set it in motion, give it a push. The impression is clear; it is the blow given by $A$ which makes $B$ go, which produces B's movement' ([1946] 1963, 20).

Michotte ran a lot of variants of the experiment, for example with varying lengths of delay between the contact of the green square and the motion of the red square, and, instead of having the green square move until it touched the red one, having spatial gaps of various sizes between the place where the green square stops and the red square. He found that the number of observational reports that invoked causal concepts dropped off sharply when the spatial or temporal gap between the two movements got big enough. He also ran experiments involving what he called 'qualitative causality'; for example, in one experiment a green circle is next to a red circle. The green circle suddenly changes colour from green to yellow, whereupon the red circle changes from red to blue. He found that subjects did not describe such sequences in causal terms: the 'most frequent impression was one of a succession of independent events' ([1946] 1963, 243). (See also this volume, Chapter 21, §2.)

Michotte took himself to have made two important discoveries: first, that we do perceive - that is, have experiences as of - one thing causing another (or, in Michotte's terms, we have a 'causal impression'), but, second, that such experiences are fairly tightly circumscribed: they only arise in cases that have certain kinematic features. He also hypothesised that the mechanism that generates the causal impression is innate (see Saxe and Carey 2006).

Let's concentrate for now on the first claim. Does the fact that, when asked to describe what they see in the basic case described above, subjects typically respond by invoking causal concepts like 'pushing', 'shoving', and 'making the ball go' establish that causal experiences are possible? (Michotte's claim here is, of course, similar to Anscombe's and Ducasse's claim that we can straightforwardly perceive cutting, a branch being caused to bend, and so on.) The consensus is that the possibility of causal experiences is not established by such reports just on their own. Susanna Siegel provides a nice example of the dangers of 
reading off the contents of experience from observational reports: one person might report that a table looks to be, say, five metres away, while another, in the same situation, might report that it looks seven metres away. But it would be rash to conclude that how the table looks really differs between the two people, since it might easily be that the difference in the reports is due solely to a difference in how good the observers are at judging distances (see Siegel 2009, *ms 4).

One way to approach the issue is to consider the extent to which subjects' reports are affected by background information. One would expect that if the reports are really 'inferred' from background information, then one would be able to change the contents of the reports by varying the background information. For example, imagine seeing a cartoon of Jerry running around with Tom hot on his heels. It might be that observers describe what they see differently, depending on the preceding portion of the cartoon: if this involved Jerry just managing to escape from Tom's clutches, then they might describe it as Tom chasing Jerry. But if it involved Jerry tying an invisible wire to a sleeping Tom and then to himself, then they might describe it as Jerry pulling Tom along. If so, this would arguably show that chasing and pulling are not really 'perceived' features of the cartoon, since which feature is reported varies with different background information.

This conception of how to decide whether, or to what extent, a given element is part of our perceptual experience trades on the claim that perception is modular, and that perception is 'informationally encapsulated': that is, perceptual experience is not fully penetrated by all the perceiver's background information. The Mueller-Lyer illusion is a standard example - the lines still look to be different lengths to most people, even when they know that they are in fact the same length - whereas in the Tom and Jerry case, whether or not Tom is reported as chasing Jerry depends upon what the observer's background beliefs are. (See Fodor 1984 for a discussion of modularity in the context of the theory-ladenness of observation.)

In the causal case, then (assuming that perception is indeed modular), the question is whether subjects' causal reports of experience - reports that invoke causal concepts like 'pushing', 'making the ball go', and so on - are sensitive to all of their background information. Michotte's own experiments provide prima facie evidence that such reports are not sensitive to all of the subject's background information, since the subjects are fully aware that the squares moving across the screen are not really causally interacting at all; it's not as though they are looking at actual interactions between moving blocks of wood, say. So one 
can think of Michotte's experimental set-ups as a kind of causal illusion: the sequences appear causal to the observers, even though they know that they are not.

There is considerable psychological evidence that causation is indeed perceived in this sense (for example, Schlottmann and Shanks (1992) describe an experimental situation in which short-term associative learning does not affect causal experience). As Brian Scholl and Patrice Tremoulet put it, the "phenomena of perceptual causality are mandatory in the way that most visual illusions are: to the degree that the events are clearly perceived ..., the causal ... nature of the resulting percepts is nearly irresistible. This reflects a type of encapsulation: despite the fact that observers know that the displays are not really causal ..., this knowledge does not appear to be taken into account by the mechanisms that construct the percepts' (2000, 306; see also Schlottmann 2000).

\subsection{Causal experience and phenomenal difference}

Susanna Siegel (2009) argues for a second way of answering the question, whether causation can be represented in experiences. Siegel deploys what might be called a 'method of phenomenal contrast'. The general idea is as follows. First, find a particular case where the very same observable situation might plausibly be capable of producing different experiences. One example Siegel gives is playing catch indoors. You fail to catch the ball, which lands in a plant pot, and, just afterwards, the lights go out. Of course, you don't believe that the landing of the ball caused the lights to go out; nonetheless, it may seem to you that it did. In other words, 'the successive events seem to be unified in experience in a way that is not merely temporal' $(* \mathrm{~ms}, 6)$. On the other hand, it may equally not seem that way: your 'visual experience represents the ball's trajectory and its landing, and your visual experience represents the lights going out, but so far as your visual experience is concerned, these events merely occur in quick succession' (*ms, 6). The thought is that both such experiences are possible. Second, if this phenomenological claim is true, what does it show? Well, the phenomenal contrast requires explanation. If - as Siegel argues - the best explanation is that one experience represents the situation causally and the other does not, then we have good grounds for thinking that causal experience is possible.

Siegel considers and rejects two alternative explanations: that the 'unity' in the first case is somehow not causal unity, and second, that there are two components to the 'experience': a sensory element (which has no causal content) and a cognitive element (such as 'a disposition to form a causal belief'), so that what is lacking in the second case is cognitive rather than sensory $\left({ }^{*} \mathrm{~ms}, 12\right)$. This leaves Siegel's own hypothesis, that the first 
case really is a case of an experience - and not of the two-component variety - that represents the scene as causal, as the best candidate explanation of the phenomenal contrast between the two cases.

Siegel's method provides an alternative to the encapsulation criterion described in the previous section. For Siegel, the issue is not whether or to what extent our observational reports can vary with differences in background information; the central phenomenological claim is that there can be phenomenal difference, holding everything else fixed - and so without any difference in background information. Whether Siegel's method provides a better alternative is a matter for dispute. One reason for scepticism is that the claim that there are, in fact, cases of phenomenal contrast is an empirical one for which there is no evidence beyond the fact that, allegedly, we are able to imagine that one might, for example, see the ball landing and the lights going out as causally related, or, alternatively, one might not given exactly the same background information. But it is unclear whether what the reader is casually able to imagine correlates especially well with the empirical facts of the matter. So empirical support is required if Siegel's method is to get off the ground, since we need to be sure that the facts for which attribution of causal experience is claimed to be the best explanation really are facts.

\subsection{Causal perception and 'categorical' perception}

Stephen Butterfill (2008) advances a third strategy for arguing that causation can be perceived, which draws on an analogy with the psychology of speech perception. There is evidence that speech perception is 'categorical'. In one experiment, Alvin Liberman and Ignatius Mattingly (1985) present subjects with twelve sounds, evenly distributed along the spectrum of sounds from 'da', through 'ga', to 'ba'. The difference between each sound and its neighbour cannot, in most cases, be detected; however, subjects are able to discriminate at two significant points: where they hear the sound changing from 'da' to 'ga' and where they hear it changing from ' $\mathrm{ga}$ ' to 'ba'. In other words, the sounds in themselves do not fall into three distinct categories: there is no more difference between the last member of the first perceived category and the first member of the second perceived category than there is between any two adjacent members of the same category. And yet subjects report the sounds as falling into these three distinct categories: they notice distinctive changes at two points as they proceed along the spectrum. Moreover, these reported boundaries match up with the 'intended phonic gestures': 'da', 'ga' and 'ba'. What explains this coincidence? Liberman and Mattingly suggest that the best explanation is that the objects of speech perception are 
not the sounds themselves, but the intended phonic gestures. In other words, roughly speaking, we do not hear mere sounds and then interpret them as elements of speech (say, when hearing someone utter the sentence, 'there's a banana'); rather, we hear them as elements of speech.

Butterfill suggests that Liberman and Mattingly's strategy can be applied to the case of causal perception too. Experiential reports in Michotte-type sequences also exhibit category boundaries; for example, when successively longer delays are introduced in between the first circle making contact with the second and the second beginning to move, where the length of delay is increased by the same, minute, amount each time, the point at which experience stops being reported in causal terms does not vary much between observers. In the speech case, there were no category boundaries between the sounds themselves, but only between the sounds qua intended phonic gestures. Similarly, in the causal case, there is no boundary between the sequences that observers report in causal terms and those they do not, if we just consider kinematic features of the sequences; the increase in delay between the last sequence reported as causal and the first sequence not so reported is just the same as the increases in delay between the other members of the sequence. Now, suppose that there is evidence that the category boundary matches up with the conditions actually required for causal interaction (or perhaps with the conditions under which causal interactions occur according to our naïve conceptions, as is suggested by White and Milne (1999)) - something which Butterfill says it is 'reasonable to conclude' $(2008, * 15)$. This correspondence needs to be explained, and, as with the speech case, the best available explanation is that causal interactions really are perceived.

\subsection{Causal experience and the consequences for metaphysics}

There is, of course, a lot more to be said about the relative merits of the three different kinds of criteria described above. However, my focus here is on the implications of the claim that causal experience is possible for the metaphysical dispute about the nature of causation, and not on precisely how we ought to draw the line between what is 'perceived' and what is 'inferred'. So let us grant that causal experience is possible, in each of the three senses described above. Is this bad news for the Humean?

I claim not. Recall the prima facie problem faced by the Humean: if causation is an extrinsic relation (a matter of the instantiation of a regularity, say), then, since the existence of a regularity is not something that can be perceived, causation cannot be perceived. But causation can be perceived; hence Humeanism must be false. If this argument is to have any 
bite, the possibility of causal experience, in any or all of the senses described above, must be shown to be incompatible with the extrinsicality of the causal relation.

I shall discuss this issue only in relation to the encapsulation criterion, since this is a commonly accepted criterion and is also the one that has been used in psychological testing of causal perception (the results of which strongly suggest that causation is indeed perceived in this sense). According to this criterion, something can be deemed the content of experience if how things look to observers (as described in their observational reports) is not penetrated by all their background information - as with the Mueller-Lyer lines, which look different lengths even to observers who know that they are in fact the same length. Thus the claim that causation is perceived in this sense is not the claim that causal experiences can be had in the absence of any background information whatever. Were we to raise the bar that high, very few things would be capable of being represented in experience. (Consider someone looking sad, for example, or a table looking square. Without prior information about what sad people typically look like, or what square things look like when observed from an oblique angle, we would not be able to experience someone as looking sad or a table as looking square.) In any case, the claim that causation can be perceived in the absence of any background information is impossible to test, since nobody - or at least nobody who is capable of being the subject of a psychological experiment - has no background information whatsoever that is relevant to causation. So the fact (if it is a fact) that background beliefs about regularities are required in order for observers to report their experience in causal terms does not undermine the claim that causation can be perceived.

It is worth noting in this regard that there is a method - the 'looking time experiment' - for testing the perceptual experiences of babies as young as four months (see Spelke 1985 for a full account). Many such experiments focus on Michotte-type sequences. For example, Oakes and Cohen (1990) provide evidence that infants as young as ten months can, in some cases, discriminate causal from non-causal sequences, just as adults do, and hence evidence that (in Michotte's terms) they, like adults, have a 'causal impression'. Rebecca Saxe and Susan Carey note that these experimental results have since been reproduced in seven-monthold infants $(2006,151)$.

What does this show? Well, Saxe and Carey (2006) evaluate the evidence for claims about the source of causal representations, and in particular for Michotte's hypothesis that the mechanism that generates the causal impression is innate. One of their conclusions is that, on the innateness issue, the existing psychological literature delivers no decisive evidence one way or the other. After all, 'by the time experimentalists can find robust evidence of causal 
perception, infants have already had six months of experience observing causal interactions' (Saxe and Carey 2006, 163). In other words - as I said above - nobody capable of being the subject of a psychological experiment has no background information whatsoever; and the background information available even to six-month-old babies includes plenty of regularities, including broadly Michotte-type sequences.

In any case, even if we could somehow show that causal experience is possible in the absence of any relevant experience of regularities, it is unclear why this would be incompatible with a broadly Humean account of the nature of causation. It might be that human beings have an innate capacity to differentiate between the kinds of kinematic sequence that are, in fact, typically causal (as in the standard Michotte-type launching events with no spatial gap or temporal delay between contact of one object on the other and the movement of the second) and those that are not (as in Michotte's cases with significant spatial gap or temporal delay). This would in no way compromise the claim that sequences of the first kind are causal in virtue of instantiating regularities, rather than in virtue of an intrinsic relation that can be the object of 'direct awareness'.

On the other hand, the possibility of causal experience in the absence of background information concerning regularities would refute Hume's empirical claim that the 'impression of necessary connection' only kicks in once a habit of expectation - derived from past experience of regularity - has been established. It would therefore undercut (what is normally claimed to be) Hume's argument for the claim that causation is not an intrinsic relation (or that we have no evidence that such an intrinsic relation exists), which relies on the premise that we cannot experience causation in 'single instances of the operation of bodies' (see Fales 1990 23-30). And of course the less controversial claim that causal experience is possible at all - whether or not it is possible in the absence of background information about regularities - by itself undercuts the standard argument for Humeanism with which I started this chapter: that, since causation is unobservable simpliciter, we have good grounds for rejecting the view that causal relations are intrinsic (though we already saw in $\S 2$ that there are independent reasons for rejecting this argument in any case).

\section{Non-visual causal experience}

In this section, I briefly discuss two other ways, aside from the visual, in which causal relations have been thought to be perceivable: the cases of agentive ( $\$ 4.1)$ and tactile $(\S 4.2)$ experiences. The case of agentive causation does not, so far as I can tell, raise significantly different issues for the metaphysics of causation than does the visual case, so I shall not 
discuss its implications for metaphysics, except to point out a connection between agentive experience and agency theories of causation in $\S 5$. The case of tactile experience has been much less discussed, and so I shall spell spend a little time discussing its ramifications.

\subsection{Agentive experience}

One part of Hume's argument that we do not have an impression of necessary connection that licenses a priori inference from causes to effects concerns the operation of the will ([1748/51] 1975, 64-9). Predictably, the argument focuses on various things we would be able to know, were we to be able to discern a necessary connection between acts of will and (for example) bodily movements, which manifestly we do not know. I shall not describe Hume's argument or what is wrong with it here (but see Menzies 1998, 345-8 for a quick summary of both); what I am interested in is whether, by contemporary lights, there are any grounds for supposing that we $d o$, in fact, have what (following Bayne 2008) I shall call agentive experiences: experiences as of acting intentionally, that is, as of bringing something about specifically as an agent.

Of course, if visual causal experiences of causation are possible, then plausibly we can at least sometimes visually experience our own bringing things about, as when I observe myself reaching out for a coffee cup and picking it up, say. But I shall not class such experiences as agentive experiences, unless the experience somehow also includes agency as such, as opposed to mere causation. That is, a visual experience that is merely an experience as of my hand reaching out and picking up the cup - something that is phenomenologically similar to that of watching a robot's hand doing the same - will not count as agentive. An experience will only count as agentive if its content includes my performing an intentional action.

An immediate problem faced by any attempt to argue that we do have distinctive agentive experiences is that in our everyday descriptions, we seem to be just as happy to describe other people's bodily movements in intentional terms as we do our own. If I am watching an auction and I see someone put a bid in by raising their arm, the most natural way to describe what I see is to say that they raised their arm, and not merely that their arm rose up. Indeed, it is easy to imagine that we will do this, in the right context, even if we know that the 'person' is really a remote-controlled robot. Whether or not we do indeed have experiences as of other people's acting intentionally is a question I shall leave open. The prima facie problem here, however, is that we are looking for a distinctively first-personal experience of agency: something that arises from our own 'acts of will'. So, if we are just as 
happy to describe other people's bodily movements in intentional terms as we do our own, we need to be careful not to rely solely on subjects' reports, since these may not discriminate between observation of others' intentional action and genuine, first-personal, agentive experience.

One experiment designed to provide evidence for the existence of agentive experience is Daniel Wegner's 'helping hands' experiment (Wegner 2002). Here is Siegel's description of the experiment:

[P]erson $A$ stands facing a mirror with arms inside a sleeveless robe, while person $B$, standing behind $A$, puts engloved arms through the arm holes so that $B$ 's arms are where $A$ 's would normally be. $B$ then hears instructions directing the hands (e.g., to clap, wave, make a fist). People in $A$ 's position who hear the directions report feeling a greater degree of control of $B$ 's hands ( 3 on a 7-point scale) than do people in $A$ 's position who do not hear the instructions ( 1 on a 7-point scale). (*Siegel $2005 \mathrm{~ms})$

As Siegel notes, person $A$ does not believe that she really is controlling $B$ 's hands; hence 'this feeling is a candidate for being an experiential representation of efficacy' ('experience of efficacy' being Siegel's name for what I am calling 'agentive experience'). This connects with the modularity thesis described in $\S 3.1$ above: the thought is that since how things seem is not penetrated by all the information in the subject's possession - she knows she is not in control but still has the feeling of control - the representation ('I am controlling $B$ 's hands') would seem to be delivered by the perceptual system.

Tim Bayne speculates that dissociation between judgement and perception in the case of agency is also possible in two kinds of disorder: anarchic hand syndrome and utilization syndrome. He notes:

The two syndromes are similar in that each involves an inability to inhibit stimulus-driven actions. The patient with an anarchic hand ... will take food from another's plate ...; the patient with utilization syndrome will put on multiple pairs of sunglasses, even when she is already wearing sunglasses. These actions ... may even be at odds with the patient's goals. (The patient doesn't want to take food from his neighbour's plate.) But despite their behavioural commonalities, these two disorders give rise to very different reports: whereas patients with utilization behaviour show no inclination to disown their actions, 
patients with an anarchic hand typically describe the hand as 'having a will of its own'. (Bayne 2008, 186)

Bayne contends that the differing judgements as to authorship of the actions are plausibly due to differences in phenomenology: the patient with an anarchic hand 'fails to experience himself as the agent of the movements of his anarchic hand', while the patient with utilization behaviour has normal experiences of agency. And the final step in the dissociation of perception and judgement would be to convince the patient with an anarchic hand that 'he is acting even though he doesn't experience himself as acting', or to convince the patient with utilization behaviour that 'she is not acting despite the fact that she experiences herself as acting' (ibid.). This would provide further evidence of encapsulation in the case of agency: evidence, that is, of the perceptual system delivering a verdict that is insensitive to what the patient believes to be the case.

Siegel herself (2005) deploys the same basic argument structure as she uses for the claim that we can perceive causation to argue that we can perceive what she calls our own 'efficacy'. Again, she gives a pair of examples where the stimuli and background knowledge remain the same, but where the phenomenology differs; she then offers the claim that one's own efficacy is experienced in one of the cases but not the other as the best explanation of the difference in phenomenology.

\subsection{Tactile experience}

Rather less attention has been paid to the tactile case than to the visual and agentive cases. Nonetheless, both Evan Fales (1990, Chapter 1) and David Armstrong (1997, 212-4) have taken the case of the sensation of pressure or force to strike a considerable blow against the Humean.

Fales considers the case where someone pushes steadily against your forehead with their hand, and claims to identify several components of the 'intrinsic character of the sensation of force' $(1990,16)$ : (i) it has a spatial location; (ii) it has a magnitude; (iii) it has a direction in space; (iv) several different forces can sometimes be differentiated; (v) felt forces form 'an algebra': 'they can be felt to add together in a certain way which depends upon their respective magnitudes and directions' (ibid.); and (vi) asymmetry: '[ $\mathrm{t}]$ hat production is an asymmetric relation is something we experience. We do not merely experience forces as having location, magnitude, and direction. We experience them as acting upon something ...'. For example, we 'are able to distinguish in perception between active agency on our part 
and the passive reception of force', and 'between an impressed force and the resistance of our bodies' $(1990,17)$.

Fales proceeds to mount an argument against Hume's contention that we cannot, on first observing an event of a given kind, predict what will happen next, by asking us to consider whether a subject would be able to predict whether or in what direction his head would move if subjected to a blow to the forehead (see Fales 1990 23-30). I shall ignore this part of his argument, however, and concentrate on two questions. First, are Fales's phenomenological claims true? And second, if they are, do they pose any problems for the Humean?

We are by now familiar with the point that the claim that our experiences can have causal content does not serve to refute Humeanism. So in a sense it does not much matter, for current purposes, whether Fales is right about the phenomenology if we think of the phenomenological claims as being claims about the contents of tactile experiences.

On the other hand, the case of force or pressure might seem more worrying, because it might seem more obvious in this case that force or pressure is an object of 'direct awareness' rather than merely the content of experience, broadly conceived; and Humeans (conceived as those who take causation to be an extrinsic relation) must, of course, deny this. But in fact it is not really obvious at all that pressure is an object of direct awareness. Of course, it feels different when someone presses hard on your forehead to how it feels when they press more gently; and it feels different when they press on the left side of your forehead to how it feels when they press on the right side. But none of this establishes that the pressing - or its spatial location or its magnitude - is an object of direct awareness. After all, a flute sounds different when played centimetres away from your left ear to how it sounds when played in the next room; but this does not establish that the proximity of the playing is an object of direct awareness - though of course it might well be something that is represented in one's auditory experience. Moreover, in general - to reiterate a point made in $\S 3$ above - it is unclear how one might establish what does and does not count as an object of direct awareness, in the absence of agreement about what there is in one's vicinity that is available to be a candidate for direct awareness; and such agreement is, of course, precisely what is lacking in the case of causation.

If Fales's argument is to have any impact on the metaphysical debate, then, it needs to be shown that force or pressure really is an object of direct awareness. Menzies (1993) argues directly against this claim, saying that: 
there is a counterfactual element to [causal] relations that cannot plausibly be claimed to be an object of direct awareness. Compare, for instance, the situation in which my sensation of pressure is caused by the impact on my body with the situation in which the sensation is actually caused by some other causal factor, coincidentally operating at the same time. These situations seem to differ only in terms of what is counterfactually true of them. The first situation is one in which it is true that if the bodily impact had not occurred, I would not have experienced the sensation of pressure, whereas the second situation is one in which this counterfactual is false. In determining the cause of my experience of pressure, I have to be able to determine whether this counterfactual is true or false. But it is clear that I cannot do this on the basis of my perceptual experiences, since the content of my experiences would be the same in both causal situations. It would seem, then, that ... I do not, after all, have direct, noninferential awareness of causation in this case. (Menzies 1993, 201-2)

Let's assume that by 'perceptual experiences' here, Menzies means 'direct awareness'. (I discuss whether counterfactual dependence can be experienced in a broader sense of 'experience' in $\S 5$ below.) Armstrong argues that Menzies' argument fails, because it could be that 'all that we are aware of is our body being pressed upon. Being pressed upon entails that something presses, so if our perception is veridical then something is doing the pressing. But perhaps, once collateral information (from other senses, etc.) is abstracted from, the pressure sensation involves nothing more than a quite indeterminate awareness of something or other doing the pressing' (Armstrong 2003, 228). It is unclear that Armstrong really addresses Menzies' concern here, however. Menzies' objection appears to be that the very same sensation can be produced either by genuine pressure - something pressing on me - or by something entirely different (some sort of direct stimulation of my brain by a neuroscientist, say), but where there is still, coincidentally, something pressing on my body. Genuine detection of pressure - qua causal relation - would require that I can tell the difference between these two cases, which I cannot do because the only relevant difference is a difference in the truth of the relevant counterfactual. Armstrong's suggestion appears to be that the argument fails because I cannot discern what, exactly, it is that is doing the pressing (I am only aware of 'something or other doing the pressing'); but Menzies' second case is supposed to be one where nothing that I have any awareness of is doing any pressing; the sensation of pressure is caused by something else. So pressing is not something I am directly aware of. 
Menzies' argument fails, however, for another reason. It is no objection to the claim that we are directly aware of some feature $F$ to say that a qualitatively identical experience as of $F$ can be had in the absence of $F$ itself. Consider the visual case of looking at a snooker ball: I can be directly aware of the part of the ball facing me (in the sense of the face being part of the visual stimulus). But this is perfectly consistent with there being possible cases where I have a qualitatively identical experience that is not caused by any small, red, hemispherical shape; this is something I can perfectly easily hallucinate or dream, or perhaps have induced by my brain being tweaked by a neuroscientist. Of course, in the hallucinatory case I am not directly aware of anything at all; but this does not show that in the nonhallucinatory case I am not directly aware of anything either. Similarly for the case of pressure: the fact that I can have a tactile experience that is indistinguishable from genuine direct awareness of pressure, even though that experience is not caused by pressure, does not undermine the claim of the veridical case to be a genuine case of direct awareness.

This is not to say, however, that Fales has successfully shown that force or pressure can be an object of direct awareness. Indeed, as I have said, it is hard to see how this can be shown. Brute appeal to introspection is not good enough, for we have very good reasons to doubt the reliability of introspection in such matters. Consider, for example, the case of colours. Arguably, colours seem to us to be objects of direct awareness: intrinsic, categorical properties of objects whose nature is immediately given to us in experience. But a combination of scientific discovery and philosophical reflection have shown that this is a very difficult view to maintain: plausible candidates for being intrinsic colour properties of objects (surface reflectances, say) are equally implausible candidates for being properties of which we are directly aware in sensory experience.

Now, Fales argues, in effect, that awareness of forces is not like this; on the contrary, the felt properties of forces listed above (or at least the first five of them) are precisely properties of forces as described by physics: 'they are exactly those which have been taken over into physics and given a precise representation there by means of a vector calculus' (Fales 1990, 16). But it is debatable whether the felt properties of forces really are as Fales describes them. For example, do felt forces really have a direction? If someone presses the end of my nose horizontally, it feels different to when they press the same point in a slightly upward direction. But this establishes nothing, for of course, I also have awareness of the movement of my nose as a result of the finger pressing on it, and it could just as well be that what I am directly aware of is simply the finger and the movement of my nose. 
In any case, the colour case shows that introspection is an unreliable guide to what we are and are not directly aware of, and that is enough to cast doubt on the claim that we are directly aware of forces. In the absence of a good argument that force or pressure is an object of direct awareness - as opposed to something that features in the content of experience, where (like the experience as of a billiard ball, as opposed to just its facing surface) the content of experience can be affected by background information - tactile experience of pressure, if it exists, is just another example of causal experience, and provides no more ammunition against Humeanism than do the visual and agentive cases.

\section{Other broadly Humean views}

I have so far been characterising 'Humean' views as, essentially, versions of the regularity theory of causation. But of course many philosophers who subscribe to a broadly Humean metaphysics do not hold a regularity theory of causation. Rival candidates include, in particular, counterfactual, projectivist and agency theories, and it is worth briefly discussing the connection between these views and the issues concerning causal experience.

Counterfactual theories of causation claim that causation is to be analysed, somehow or other, in terms of the notion of counterfactual dependence (see this volume, Chapter 8). We have already seen that Menzies claims that counterfactual dependence cannot be an object of direct awareness; does the same point apply to experience more broadly conceived? That is, can we not represent in experience something's being such that, had it not happened, something else would not have happened either? At first sight, the natural answer is no; as Colin McGinn puts it (in the context of colour perception): 'Your eyes do not respond to woulds or might have beens' (McGinn 1996, 540). But recall that we are here not restricting the content of experience to 'what your eyes respond to'.

Siegel speculates that counterfactual dependence is sometimes capable of being represented in experience; for example, imagine a rock balanced on the tip of another rock. It is not obvious, Siegel thinks, that we cannot represent that scene as being such that the rock would tip over if pushed $(* 2009, \mathrm{~ms} 11)$. But - as she notes - even if this is right, it only establishes that counterfactual experience is possible in cases where the antecedent ('if the rock had been pushed ...') is a 'natural continuation' of something that you see: you don't need to, as it were, imaginatively think away what is, in fact, in front of you. But many cases of counterfactual dependence are not like that; the possible situation that makes it true that had I not hit the cue ball, it would not have struck the black is one in which very little of the 
actual scene, where I do hit the cue ball, it moves across the table, and strikes the black, remains intact.

Psychologists have paid a good deal of attention to counterfactuals, but they have certainly regarded counterfactuals as falling on the side of thought rather than perception. So there is scant evidence one way or another on whether (a limited class of) counterfactuals might be capable of being represented in experience. This is of course an empirical question, but it seems unlikely that it has a positive answer. Just from everyday life it seems that 'observational' reports of counterfactual dependence are, at best, extremely rare. If this is right, then we cannot even make it to the starting line when it comes to asking whether such reports are genuinely reports of experience or not (as judged by, for example, whether they are affected by variations in background information), since there are no such reports to ask about in the first place.

From the point of view of the metaphysics of causation, though, does any of this matter? Suppose that we agreed that causal experience is possible, but counterfactual experience is not. Would this make trouble for a counterfactual analysis of causation? Arguably not. I have already argued that the fact that we cannot experience a sequence's instantiating a regularity does not undermine a regularity theory of causation when combined with the fact that we can experience a sequence's being causal; and the same basic point applies to the counterfactual analysis. Indeed, to put the point more vividly, if in general we required as a condition on an acceptable conceptual analysis $C$ of some phenomenon $X$, where $X$ is capable of being represented in experience, that $C$ is also capable of being so represented, then conceptual analysis in general would be in big trouble. Consider my experience as of seeing a person in front of me (assuming that such experience is possible). The kinds of psychological features that are standardly viewed as requirements on personhood are not, it seems, capable of cropping up in the content of experience. So according to the line of argument under discussion - personhood cannot be conceptually analysed in psychological terms.

One might argue that there are good philosophical grounds for upholding the principle just described; for example, one might subscribe to the view that the representational content of an experience is given by its truth conditions. But this would be to depart from the conception of 'perceivability' that generates a violation of the principle in the first place, for it would place constraints on what does or does not count as perceivable that are orthogonal to the constraints imposed by the kinds of psychological conceptions of perceivability that I have been discussing. Grant, for example, that observers' reports about causation are, but 
their reports about counterfactual dependence are not, informationally encapsulated. This is a purely psychological fact about the way our perceptual system works. To hold that the representational content of an experience is given by its truth conditions would be to place an additional constraint, beyond informational encapsulation, on what can and cannot be perceived; and so we would now have no reason to accept that the facts about informational encapsulation really reveal anything about what can and cannot be perceived. So we would have no reason to think that the above principle had really been violated.

A second broadly Humean view about causation - one that has a much more direct relation to the question about the possibility and nature of causal experience - is a projectivist view. On one interpretation of Hume, for example, Hume conceives of causation as a projection of our habits of expectation onto a world of loose and separate events; and that projection modifies our experience in such a way that events seem causally connected. Since this 'impression of necessary connection' provides the content for the idea of necessary connection, our causal experience plays an essential role in determining the meaning of our causal claims (see Beebee 2006, Chapter 6) - though on such a view causation is not genuinely perceived in at least one sense, since what gives sequences their causal character is contributed by the mind of the observer rather than a detectable feature of the sequence itself.

A different version of projectivism (at least in a broad sense of 'projectivism') is the ‘agency' view of causation defended by Peter Menzies and Huw Price (1993). Menzies and Price argue that causation should be seen as a secondary quality, analogous in some respects to colours, where the relevant experience, in which the concept of causation has its origin, is the experience of agency: of doing something as a means to achieving an end. They say:

[W]e all have direct personal experience of doing one thing and thence achieving another. ... It is this common and commonplace experience that licenses what amounts to an ostensive definition of the notion of 'bringing about'. In other words, these cases provide direct non-linguistic acquaintance with the concept of bringing about an event: acquaintance that does not depend on prior acquisition of any causal notion. $(1993,194-$ 5)

Arif Ahmed takes issue with this claim about the experience of agency:

I might agree with [the first sentence quote above] if you take away two letters. What we all have direct experience of is doing one thing and then achieving another. I cannot see 
that we have direct experience of anything that distinguishes 'thence' with its causal implication from 'then' which lacks them. I cannot see that the sequences in which ends are brought about by means look any different from sequences in which the former merely succeed the latter. (Ahmed 2007, 125-6)

The discussions of Siegel (2005) and Bayne (2008) briefly described earlier bear, of course, on Ahmed's contention; they at least ought to make us consider whether it is as obvious as he claims that there is no such thing as the experience of agency. On the other hand, Menzies and Price seem to want more than mere experience of agency: they want 'direct non-linguistic acquaintance with the concept of bringing about'. This would appear to be a much stronger requirement, and arguably one that cannot be shown to obtain by the kinds of psychological study envisaged by Siegel and Bayne. This is because the notion of 'direct acquaintance' is, as we have seen, a metaphysically loaded notion: we could not, for example, be directly acquainted with bringing about, if bringing-about was merely a matter of the instantiation of a regularity, say. Siegel and Bayne are (explicitly or implicitly) concerned with a broader conception of experience or perception, of the kind whose content could in principle be established independently of metaphysical presuppositions.

That said, Ahmed argues that Menzies and Price's appeal to the experience of agency, as described above, is in fact an unnecessary hostage to fortune given their overall account, which trades on a conception of agency that is analysed as decision-making on the basis of what they call 'agent probabilities' (that is, 'conditional probabilities, assessed from the agent's perspective under the supposition that the antecedent condition is realized ab initio, as a free act of the agent concerned' (Menzies and Price 1993, 190)). Ahmed argues that, since someone could 'make judgements of agent-probabilities without being able to form causal judgements' (Ahmed 2007, 131), agency, thus understood, can be thought of as conceptually prior, in the sense required for an agency theory of causation, to causation. If Ahmed is right, then an agency theory of causation does not require commitment to disputable claims about the experience of agency, although the agent's point of view - the perspective that delivers agent probabilities - remains a crucial part of the story (see Price 2007, especially 279-83).

Further reading

Hume's Treatise ([1739-40] 1978), Book I, Part III, §14, and Enquiry ([1748/51] 1975), §7, are the starting points for the debate about causal experience and its connection to Humean 
metaphysics. Ducasse 1965, Anscombe [1971] 1993 and Fales 1990, Chapter 1 are attempts to tie causal experience to singularism; see also Menzies 1998, which includes a summary of some of the psychological literature on causal perception. Beebee 2003 argues that the evidence concerning causal experience provides no justification for either Humeanism or singularism. Bayne 2008 provides a good introduction to the issues concerning agentive experience, with plenty of references. Other relevant recent articles include Siegel 2009 and Butterfill 2008.

Bibliography

Ahmed, A. (2007). 'Agency and Causation', in H. Price and R. Corry (eds.), Causation, Physics, and the Constitution of Reality (Oxford: Clarendon Press), 120-55. Anscombe, G. E. M. ([1971] 1993). Causality and Determination. Cambridge: Cambridge University Press 1971. Reprinted in E. Sosa and M. Tooley (eds.), Causation. Oxford: Oxford University Press 1993.

Armstrong, D. M. (1962). Bodily Sensations. London: Routledge \& Kegan Paul. -- (1993). 'Reply to Menzies', in J. Bacon, K. Campbell and L. Reinhardt (eds.), Ontology,

Causality and Mind: Essays in Honour of David Armstrong, Cambridge: Cambridge University Press, 225-32. -- (1997). A World of States of Affairs. Cambridge: Cambridge University Press.

Bayne, T. (2008). 'The Phenomenology of Agency', Philosophical Compass 3, 182-202. Beebee, H. (2003). 'Seeing Causing'. Proceedings of the Aristotelian Society 103, 257-80. -- (2006). Hume on Causation. London: Routledge.

Blackburn, S. (1984). Spreading the Word. Oxford: Oxford University Press.

Butterfill, S. (2008). 'Seeing Causings and Hearing Gestures', Philosophical Quarterly.

[*Issue and pages nos. to be inserted later]

Cartwright, N. (2000). 'An Empiricist Defence of Singular Causes', in R. Teichmann (ed.), Logic, Cause and Action. Cambridge: Cambridge University Press.

Coventry, A. (2006). Hume's Theory of Causation: A Quasi-realist Interpretation. London: Continuum.

Ducasse, C. J. (1965). 'Causation: Perceivable? Or Only Inferred?', Philosophy and Phenomenological Research 26, 173-9.

Fales, E. (1990). Causation and Universals. London: Routledge.

Fodor, J. (1984). 'Observation Reconsidered', Philosophy of Science 51, 23-43. 
Goldman, A. I. (1993). 'The Psychology of Folk Psychology', in A. I. Goldman, ed., Readings in Philosophy and Cognitive Science (Cambridge, MA: MIT Press, 1993), 34780.

Hume, D. ([1739-40] 1978). A Treatise of Human Nature. L. A. Selby-Bigge and P. H. Nidditch, (eds.), $2^{\text {nd }}$ edition. Oxford: Clarendon Press.

-- ([1748/51] 1975). Enquiries Concerning Human Understanding and Concerning the Principles of Morals. L.A. Selby-Bigge and P.H. Nidditch (eds.), $3^{\text {rd }}$ edition. Oxford: Clarendon Press 1975.

Kail, P. J. E. (2001). 'Projection and Necessity in Hume', European Journal of Philosophy 9, 24-54.

Langton, R. \& D. K. Lewis (1998). 'Defining Intrinsic', Philosophy and Phenomenological Research 58, 333-45.

Liberman, A. M. \& I. G. Mattingly (1985). 'The Motor Theory of Speech Perception Revised'. Cognition 21, 1-36.

Mackie, J. L. (1974). The Cement of the Universe. London: Oxford University Press.

McGinn, C. (1996). 'Another Look at Color', Journal of Philosophy 93, 537-53.

Menzies, P. (1993). 'Laws of Nature, Modality and Humean Supervenience', in J. Bacon, K.

Campbell and L. Reinhardt (eds.), Ontology, Causality and Mind: Essays in Honour of David Armstrong, Cambridge: Cambridge University Press, 195-225.

-- (1998). 'Are Humean Doubts about Singular Causation Justified?', Communication and Cognition 31, 339-64.

-- (1999). 'Intrinsic versus Extrinsic Conceptions of Causation', in H. Sankey (ed.),

Causation and the Laws of Nature, Dordrecht: Kluwer, 313-29.

Menzies, P. \& H. Price (1993). 'Causation as a Secondary Quality', British Journal for the Philosophy of Science 44, 187-203.

Michotte, A. ([1946] 1963). La Perception de la Causalité. Louvain: Institut Supérieur de Philosophie. English translation: The Perception of Causality, trans. T. R. Miles and E. Miles, Aylesbury and Slough: Hazell Watson \& Viney, 1963.

Oakes, L \& L. Cohen (1990). 'Infant Perception of a Causal Event'. Cognitive Development 5, 193-207.

Price, H. (2007). 'Causal Perspectivalism' in H. Price and R. Corry (eds.), Causation,

Physics, and the Constitution of Reality (Oxford: Clarendon Press), 250-92.

Saxe, R. \& S. Carey (2006). 'The Perception of Causality in Infancy'. Acta Psychologica $123,144-65$. 
Schlottmann, A. (2000). 'Is Perception of Causality Modular?', Trends in Cognitive Science $4,441-2$.

Schlottmann, A. \& D. Shanks (1992). 'Evidence for a Distinction between Judged and Perceived Causality', Quarterly Journal of Experimental Psychology 44, 321-42.

Scholl, B. J. and P. D. Tremoulet (2000). 'Perceptual Causality and Animacy'. Trends in Cognitive Science 4, 299-309.

Siegel, S. (2005). 'The Phenomenology of Efficacy', Philosophical Topics 33, 265-84.

-- (2009). 'The Visual Experience of Causation', Philosophical Quarterly [*Issue and pages nos. to be inserted later]

Sosa, E. \& M. Tooley (1993). 'Introduction', in Sosa and Tooley (eds.), Causation. Oxford: Oxford University Press, 1-32.

Spelke, E. S. (1985). 'Preferential looking methods as tools for the study of cognition in infancy', in G. Gottlieb \& N. Krasnegor (eds.), Measurement of Audition and Vision in the First Year of Postnatal Life, Norwood, NJ: Ablex, 323-63.

Strawson, G. (1989). The Secret Connexion. Oxford: Oxford University Press.

Wegner, D. (2002). The Illusion of Conscious Will. Cambridge, MA: MIT Press.

White, P. \& E. Milne (1999). 'Impressions of Enforced Disintegration and Bursting in the Visual Perception of Collision Events'. Journal of Experimental Psychology: General $128,499-516$.

Wright, J. P. (2000). 'Hume's Causal Realism', in R. Read \& K. Richman (eds.), The New Hume Debate, London: Routledge, 88-99. 